Maphalala, M. C. et al. Online Learning as a Catalyst for Self-directed Learning in Universities during the COVID-19 Pandemic

\title{
Online Learning as a Catalyst for Self-directed Learning in Universities during the COVID-19 Pandemic
}

\author{
Mncedisi Christian Maphalala*1, Rachel Gugu Mkhasibe ${ }^{2}$ \& Dumisani Wilfred Mncube ${ }^{2}$ \\ *Corresponding Author: 25787810@nwu.ac.za \\ 1. North West University, School of Professional Studies in Education Studies, Mahikeng, South Africa \\ 2. University of Zululand, Faculty of Education, Richards Bay, South Africa \\ Received : 2021-06-10 \\ Revised : 2021-07-28 \\ Accepted : 2021-08-21
}

$10.46303 /$ ressat.2021.25

\begin{abstract}
How to cite this paper: Maphalala, M. C., Mkhasibe, R. G. \& Mncube, D. W. (2021). Online Learning as a Catalyst for Self-directed Learning in Universities during the COVID-19 Pandemic, Research in Social Sciences and Technology, 6(2), 233-248.

https://doi.org/10.46303/ressat.2021.25
\end{abstract}

This is an Open Access article distributed under the terms of the Creative Commons Attribution 4.0 International license (https://creativecommons.org/licenses/by/4.0/).

\begin{abstract}
The COVID-19 pandemic accelerated the use of online learning and self-directed learning to motivate and engage students. Therefore, this study sought to determine how online learning fostered self-directed learning at a South African university during this period. Higher education institutions worldwide had to shut down indefinitely following guidance from health experts to contain the spread of the COVID-19 pandemic. Since education is regarded as a pillar of development for all countries, some means had to be found to keep teaching and learning going irrespective of the ongoing health crisis. Hence, online learning made it possible for university students to continue learning during the emergency university closure. This was a period of reckoning, however, as many students began experiencing challenges related to poor internet connectivity and accessing digital learning devices. Despite these challenges, the solution was to reach out to all students to ensure that they were not excluded from the learning process. The sudden transition to online learning meant that students could no longer follow a well-coordinated, structured learning schedule that was guided and supervised on campus; rather, online learning meant they had to become more independent in their learning. Independent learning encourages students to be proactive and independent, a philosophy aligned to self-directed learning (SDL). This study explored the experiences of third-year student teachers in navigating SDL through online learning platforms. The study was underpinned by self-directed learning theory and adopted a qualitative case study research design, generating data from ten student teachers using a Zoom App focus group discussion. Data were analyzed using an inductive thematic analysis framework. The study found that although SDL is appropriate because it promotes learning independently, the majority of student teachers encountered several challenges when adopting online learning, catching them off guard because they were not formally introduced to it.
\end{abstract}

Keywords: Online learning, self-directed learning, learning management system, independent learning, connectivity, digital divide 
Maphalala, M. C. et al. Online Learning as a Catalyst for Self-directed Learning in Universities during the COVID-19 Pandemic

\section{Introduction}

South African institutions of higher learning have been in denial with regard to implementing reforms in relation to the mode of teaching and learning. It took the outbreak of the coronavirus pandemic (Covid-19) to transit indefinitely from a face-to-face (lecture-centered) approach to online learning (e-learning). Over the years, almost all South African universities have calibrated their program offerings around face-to-face learning models for the sake of convenience (Baez, 2019; Mgqwashu, 2017). In times of emergency such as Covid-19, the physical classrooms that are available for traditional methods (lecturer-centered) suddenly become inaccessible. This state of play raises serious questions about the future of the face-toface learning approach, hailed for its real-time contact and prompt feedback to the student (Baticulon et al. 2021; Waghid, 2018). The emergence of e-learning platforms took advantage of the established internet connectivity, better known as online learning, a term widely used to describe an emerging approach to learning through advanced communication technologies (such as Blackboard, Moodle, YouTube, virtual reality) either asynchronously or synchronously (Mpungose, 2020; Ohlin, 2019). The evolution in online learning platforms (learning management systems) (LMS), as Khoza (2019) alleges, has led to renewed interest in adapting traditional face-to-face pedagogy to a student-centered approach characterized by selfdirected learning (SDL).

Waghid (2018) predicts an era dominated by online learning, which will revolutionize and transform the higher education landscape in ways never seen before. In his work, collaborative technologies enable greater opportunities for learners' SDL with open access textbooks, ebooks, learning repositories, social networking technologies, Web conferencing, and open education resources (OER). The next section gives a detailed account of a few trends and historical markers, culminating in online learning as a catalyst for the SDL movement, an important shift towards the use of more free and open content. Again, this study presents a critical review of a broad range of factors that have an impact on student performance and satisfaction within the online learning environment.

\section{Research Questions}

This study sought to answer the following main research question: "How has online learning fostered self-directed learning in universities during the Covid-19 pandemic?"

The following four sub-questions were formulated in line with the main research question:

- What strategies were used to integration of self-directed learning in online learning environment?

- How has online learning promoted independent learning and empowerment amongst the student teachers

- Which self-directed learning approaches did the academics adopt to easily navigate online learning?

- In what ways did individual students use self-assessment and peer assessment to enhance their own learning. 
Maphalala, M. C. et al. Online Learning as a Catalyst for Self-directed Learning in Universities during the COVID-19 Pandemic

\section{Review of Related Literature}

\section{Understanding self-directed learning}

The Covid-19 pandemic spared no one as it severely affected many pillars of our society, including institutions of higher education worldwide. March 2020 marked an abrupt end to face-to-face learning within the four walls of lecture halls, and a move towards a transformed SDL mode, a new normal for most institutions in developing countries (Crawford et al., 2020; Roberson et al., 2021). The pace of the community spread of the Covid-19 pandemic resulted in a nationwide lockdown being imposed in South Africa, which accelerated the implementation of distance learning underpinned by SDL and digital learning. Baez (2019) and Morris and Rohs (2021) argue that SDL is a process that makes students responsible for planning, undertaking and reviewing aspects of their learning process. This sentiment has also been advanced by Voskampa et al. (2020), who call this transition the biggest undertaking of the 21st century. The conclusions drawn from this analysis underscore the much-needed shifts to SDL competency at both the Department of Higher Education and higher education institutions to master digital pedagogy and related technologies (Adinda \& Mohib, 2020). The transition has shown success in Western countries, and been proven to enhance academic performance and foster student engagement (Rashid \& Asghar, 2016).

Morris and Rohs (2021, p. 1-2) report that "individuals should be able to identify and set goals, motivate themselves, and develop resilience and confidence to pursue learning throughout their lives" because it allows them to adapt to change easily. Huang et al. (2020) stress that this new pedagogical approach inspires students to engage in SDL through the use of online learning. The findings of the study by Rashid and Asghar (2016) also reveal that the use of digital technology has a direct positive influence on students' engagement and SDL; however, there is no direct correlation between technology use and academic performance. This implies that SDL contributes positively when used with digital technology; individual engagement with technology is therefore paramount in achieving good results.

Although SDL has played a peripheral role in the formal education systems in South African higher education, to be successful it requires internet connectivity and digital facilities to achieve expected goals (Bonk \& Lee, 2017; Tadesse \& Muluye, 2020). It is common knowledge that the majority of academic institutions were ill-prepared owing to a lack of proper planning, unreliable internet connectivity, lack of educational resources (laptops, desktops, PDA etc.). Despite this drawback, studies reveal that learning tasks were personally meaningful, interesting and enjoyable, with a sense of control and personal autonomy (Tadesse \& Muluye, 2020). Given the alternatives to the face-to-face model, the SDL-imposed principles of selfdiscipline, self-confidence, independence, goal-oriented, persistence and enjoyable learning meant that students were never ready to embrace SDL (Bonk \& Lee, 2017). These students were accustomed to being extrinsically motivated, less likely to look for opportunities, and dependent on others for their learning (Li et al., 2020; Roberson et al., 2021). They value teacher-driven instructions and are less likely to explore learning experiences which give rise to creativity and participative ways in the world at large. 
Maphalala, M. C. et al. Online Learning as a Catalyst for Self-directed Learning in Universities during the COVID-19 Pandemic

\section{The transition to online learning}

The emerging trend in education has seen a high demand for modern physical resources (technological tools) in universities. Studies conducted by Mpungose $(2019,2020)$ and Khoza (2019) underscore the role of modern physical resources (computers, mobile phones, i.e. smartphones, and others) for effective online teaching and learning. The challenge facing both lecturers and students is to what extent these resources can be useful in providing opportunities to support students' learning and how to integrate them into the curriculum (Baez, 2019). Considering the socioeconomic background of students in historically black universities on the one hand, and the weak financial support available from these universities on the other, a large population of students struggle to access the recommended modern physical resources such as iPads, desktop computers, webcams, laptops mobile phones, to name few (Khoza, 2019; Mpungose, 2020). These cutting-edge resources have opened up more possibilities for students, allowing easy access to study material and assignments, easy storage of information and easy retrieval of assessments, as well as allowing students to upload examination scripts anytime and anywhere (Baticulon et al., 2021; Mpungose, 2020; Waghid, 2018). In essence, for learning to take place, physical and geographical location has no material impact on access to available educational material for both lecturers and students. Khoza (2019) demonstrates that online platforms require sophisticated software resources which build education capability to empower physical resources to communicate learning. Bates (2019) categorizes software resources to include, but not to be limited to, learning management systems (LMSs) (Moodle, Canvas), software packages (Microsoft Office 365), internet browsers (Firefox, Chrome) and social media sites (Twitter, Facebook). It is fair to conclude that the evolution of various powerful open course ware (Moodle, Blackboard etc.) and social networking sites (WhatsApp, Facebook, Twitter, Linkedln, Instagram, Snapchat, Pinterest, Reddit, TikTok) has revolutionized both online learning and SDL.

\section{International perspectives on online learning and self-directed learning}

Developed countries like the United States of America and the United Kingdom experienced disruptions to academic tuition during Covid-19, but their transition to SDL through online teaching was smoother and less demanding (Crawford et al., 2020; Ohlin, 2019). Similar experiences in China, as observed by Xue Li and Xu (2020), resulted in the Ministry of Education setting up and encouraging the implementation of online education at all levels during the Covid-19 pandemic. In essence, educational information, infrastructure, educational resources and human resources, as the essential conditions for online education, were also the main content of the policy formulation and implementation of educational information (Baez, 2019; Xue et al., 2020). Pham and Ho (2020) assert that during and after the Covid-19 outbreak, the higher education sector in Vietnam became a big "laboratory of e-learning hubs" which led the global fight against the spread of Covid-19. In the case of Vietnam, university lecturers and students personally experienced SDL while using e-learning platforms. Pham and Ho (2020) reveal that more room for e-learning was provided and current regulations were reviewed regarding university curricula and syllabuses. Similarly, private universities in Egypt never encountered any challenges when shifting to SDL because the tools used for online classes were well known to both lecturers and students before the Covid-19 crisis (Mpungose, 2020). These tools included Blackboard, Moodle, email and Zoom (Crawford et al., 2020). Pham and Ho (2020) 
Maphalala, M. C. et al. Online Learning as a Catalyst for Self-directed Learning in Universities during the COVID-19 Pandemic

confirm what is highlighted by Crawford et al. (2020), when they state that prior to the global outbreak of Covid-19, some institutions in well-developed countries were already laying the groundwork for a new approach, namely SDL, to higher education.

The short synopsis of the situation in higher education institutions in both developed and developing countries given above has not touched on the situation experienced by student teachers and the use of online teaching amid Covid-19. Several researchers have indicated that Covid-19 accelerated the use of online learning and SDL to motivate and engage students (Adinda \& Mohib, 2020; Baticulon et al., 2021). However, most student teachers find it difficult to integrate SDL in their practice (Voskampa et al., 2020) because, firstly, most of the learning material (slides) on Moodle or any other digital facilities is inaccessible to some students, and those who can access them find them difficult to use. Moreover, there is a direct positive relationship between SDL and digital technology (Roberson et al., 2021; Voskampa et al., 2020).

Secondly, student teachers are expected to go to schools and do their teaching practice to meet the requirements of their programs. Most schools have changed the pattern of attendance of learners to observe social distancing. The question is, how are student teachers going to go to schools if the schools have changed their ways of teaching? Some of the schools are practicing $\mathrm{SDL}$, where learners are taught online, whereas the majority of higher education institutions have not yet introduced student teachers to the new pedagogical knowledge required to accommodate online learning. To affirm the above assertion, the findings of Ibrahim et al. (2019), in their paper titled 'Trainee teachers' readiness towards 21st century teaching practices", reveal that some student teachers reported that their preparation for practical teaching at university is insufficient because it does not provide them with adequate skills to teach in the 21st century, and they therefore find themselves ill-prepared. This is very difficult for student teachers because teachers are regarded as agents of change. Therefore, they are expected to finish their teaching practice program well equipped with all the qualities and values needed to face this challenging era (Ibrahim et al., 2019; Ohlin, 2019).

\section{Theoretical orientation}

This study was underpinned by the self-directed learning theory (SDLT) propounded by Knowles in the 1980s. Self-guided study aims to promote a spirit of self-reliance and a sense of responsibility for own learning. Knowles (1980) had many ideas that would later define SDL:

It has been defined as "a process in which individuals take the initiative, with or without the help of others," to diagnose their learning needs, formulate learning goals, identify resources for learning, select and implement learning strategies, and evaluate learning outcomes.

Moreover, SDLT identifies specific personal factors that influence learning as the main focus of this study. These personal factors include, among others own intentions and attitudes. In this study, students' SDL refers to students' perceptions of their independent learning, their sense of responsibility for their learning, and their initiative in learning. This theory argues that students take an active role in learning tasks such as reading online learning material and completing classroom tasks (Baez, 2019; Geng, Law, \& Niu, 2019). Most studies draw a comparison between features underpinning SDL and those of self-regulated learning. According to Broadbent (2017), SDL has been found to have different predictive value among 
Maphalala, M. C. et al. Online Learning as a Catalyst for Self-directed Learning in Universities during the COVID-19 Pandemic

online users in times of emergency. In theory, technological readiness concerns individual attitudes towards the introduction of new technology. In essence, students' perceptions at times reflect the learning effectiveness and learning experience of students in a course. Broadbent (2017) argues that SDL complements technological readiness and drives students' learning behavior, as well as their learning experience and perceptions, towards online learning. It is worth noting that SDL tends to use online learning platforms as the main resource to search for information (Geng et al., 2019). Studies on SDL with technology (SDLT) reveal that students' perceptions of collaborative learning can enhance their SDL. Student SDL processes contribute to the use of internet communication technology for collaborative learning (Lee et al., 2014).

\section{Research methodology}

\section{Context}

The South African university that was used as the research site has been using a learning management system (LMS) since 2009 to optimize and support student learning. Snowball and Mostert (2010) state that LMS is an umbrella term for describing the software tools used to manage students' learning, assessments and interventions. Moodle is a popular open-source learning management system that delivers a set of learner-centric tools and collaborative learning environments that empower both teaching and learning at a South African university. Moodle builds the tools into an interface that makes the learning task central. It is built on social constructionist pedagogy, including the tools that are required in an online learning environment. The e-learning community is growing at this South African university and hence an e-learning strategy has been formulated aimed at integrating e-learning into teaching and learning through the use of Moodle as an e-learning platform. The e-learning strategy has the potential to actualize the South African university's teaching and learning vision in three areas in order to:

- Help students to become self-actuated learners who are able to use technology to find information and to solve problems;

- Assist the teaching staff through the use of technology to handle routine administrative tasks, which are particularly time-consuming, given large student numbers; and

- Expand access for non-traditional students, through the use of asynchronous course material and blended learning, so that these students can complete degree requirements in their own time. To achieve these ideals, departmental e-learning communities of practice were established through a series of workshops for the purpose of developing academic staff to embed e-learning technologies for effective learning.

The outbreak of COVID-19 in the year 2020 which led to the closure of universities, immediately forced this South African university into emergency transition to fully online teaching and learning to ensure the continuity of academic activities. The COVID-19 pandemic accelerated the use of online learning and self-directed learning to motivate and engage students.

\section{Research approach}

For this study, a qualitative research approach was chosen to explore the experiences of thirdyear student teachers in navigating SDL through online learning platforms, as a result of a 
Maphalala, M. C. et al. Online Learning as a Catalyst for Self-directed Learning in Universities during the COVID-19 Pandemic

sudden transition to online learning forced upon by Covid-19 lockdown at a South African university. According to Creswell and Plano-Clark (2011), a research approach is a decisionmaking process in research that assists the researcher in making informed selection of design, methods, data collection instruments, data analysis and interpretation procedures, and how results will be presented.

\section{Sample}

Polit and Hungler (1999) refer to the population as an aggregate or totality of all the objects, subjects or members that conform to a set of specifications. In this study, the population was made up of third-year student teachers at a South African university. The study made use of the non-probability purposive sampling to select ten of third year student teachers at a South African university, made up of 6 female and four male students ranging between the ages of 22 and 26 years of age. Purposive sampling is used when the researcher has to research participants that need to meet very specific criteria; otherwise, their participation might not be useful to the study. Purposive sampling was used to identify and select student teachers who held information-rich and practical experiences of generating ideas about SDL activities due to the transition from contact to online learning. Students needed to have accessibility to an electronic device and internet and should have attended face-to-face lectures and later transitioned to e-learning due to Covid-19 pandemic. These were the main reasons this study took a posture to explore the experiences, meanings, beliefs and perspectives that participants assign to a social phenomenon (Nieuwenhuis, 2020). After recruiting participants, they signed consent forms that detailed ethical considerations such as confidentiality, anonymity and beneficence.

\section{Data collection methods and instruments}

The ten third-year student teachers participated in a Zoom App focus group discussion. Student teachers were coded as participants 1-10; wherein student-teacher 1 was represented as participant 1 and student-teacher 2 represented as participant 2, up to student-teacher 10 coded as participant 10. A Zoom App focus group discussion (FGD) lasted for a period of 1 hour 30 minutes, and the recording feature on the App was activated after consent was granted by the participants.

De Vos et al. (2011) view FGD as a suitable instrument to collect perceptions on a specific topic of interest in a permissive, non-threatening atmosphere. According to Udosen (2014), focus group discussions have the benefit of allowing the researcher to swiftly discover the fundamental concerns about the use of SDL during the Covid-19 pandemic. Another benefit is that group interviews are inexpensive, provide a lot of information, have a high level of face validity, and are flexible. They create a natural setting in which people can openly express their opinions. One participant's ideas inspire others to participate fully in conversations (Babbie, 2010; Flick, 2009). The discussion in this study guided by the FGD guide, which probed on the experiences of third-year student teachers about SDL activities as a result of the transition from contact to online learning. The focus group discussion guide used to gather data consisted of twelve questions, each of the four research questions of the study were linked to three questions out of the total. 
Maphalala, M. C. et al. Online Learning as a Catalyst for Self-directed Learning in Universities during the COVID-19 Pandemic

\section{Validity}

Efron and Ravid (2013) define validity in research as "the degree to which the study, the data collection tools, and the interpretation of data accurately represent the issue being investigated" (p. 70). The researchers ensured that the data recorded reflected the participants' views. To ensure the credibility of our results, the raw data in the form of field notes, audio recordings and transcripts were audited for accuracy. Furthermore, we also employed member checking as a way of ensuring trustworthiness where participants checked the transcripts for accuracy in their descriptions of their lived experiences.

\section{Data analysis}

All relevant data generated were thematically analyzed using Braun and Clarke (2006) phases of data analysis. This process followed six phases propose by Braun and Clarke (2006) for categorizing research data according to themes. These phases are:

I. Familiarization with the data, where the researchers actively engaged with data by firstly transcribing the interactions and then reading (and re-reading) the transcripts and listening to the recordings.

II. Generating initial codes, identifying preliminary codes, which were the features of the data that appeared interesting and meaningful.

III. Searching for themes, where relevant data extracts were sorted according to overarching themes.

IV. Reviewing themes, where the themes were checked in relation to the coded extracts.

V. Defining and naming themes, where the researchers provided theme names and clear working definitions that capture the essence of each theme in a concise manner.

After using this detailed and structured process before analysis to form categories, a more streamlined data analysis process gave rise to focused and four themes that answered the main research question and gave rise to the findings section. In the final analysis, the main research question and sub-questions guided the analysis and generated four themes as discussed under the findings section.

\section{Findings}

Four main themes were therefore generated from data to respond to the research questions namely:

\section{Theme 1: Integration of self-directed learning in online learning}

Successful integration of the SDL process into the existing curricula requires adequate preparation by both academics and students, particularly at the undergraduate level. The findings reveal that students were not ready to play a central role in their learning when the emergency transition to online learning from face-to-face learning was imposed on them. Students were thrown into the deep end as they were not prepared for either online learning or SDL. As exemplified by the extract that follows, the participants had difficulty in navigating the SDL activities in online learning environments: 
Maphalala, M. C. et al. Online Learning as a Catalyst for Self-directed Learning in Universities during the COVID-19 Pandemic

Most of us struggled to study on our own without the lecturer teaching us; lecturers posted the slides and some notes, and we had to study on our own without somebody explaining to us. We realised we're going to fail and started on our own, trying to find answers from all sources and each other as students. (Participant 4)

SDL requires that students are assisted and guided to learn independently. However, students were not adequately prepared for the SDL process before they moved to online learning. To explain this, one participant said:

To tell the truth, our lecturers have never prepared us to take so much responsibility for our studies. They would prepare slides when they come to class, explain everything to us, and we would ask questions where we did not understand. We did receive assignments to do on our own, but when we were on campus lecturers took us through what was expected, so we had clear guidance. (Participant 9)

SDL is closely associated with the concept of a student-centered approach, which emphasizes a mechanism in which students take charge of their own education. Face-to-face or contact learning did not foster SDL among the students as they had regular access to their lecturers. Online learning platforms were used for the announcement and uploading of information for the students, and not for meaningful learning. One participant had this to say:

This serious online learning thing is new to us. Yes, we're using Moodle, but it was for accessing learning materials and notices from lecturers. Some lecturers did not even use Moodle for teaching; they only relied on teaching in class and handouts. I think online learning forced us not to rely more on lecturers, but on ourselves and each other as students. (Participant 6)

\section{Theme 2: Independent learning and empowerment}

Online learning has forced students to develop effective independent learning strategies. Students are required to formulate their own goals, study independently and reflect upon their learning in an environment where there is less oversight from academics. University is a space in which students should formulate their own goals, study independently and reflect on their learning throughout their studies. This provides the students with the flexibility to schedule and learn whenever and however it is convenient for them to do so. In another example, one student teacher indicated that:

[...] are required to take control of our studies. In the absence of lecturers in front of us, we have to decide on our own what we need to know and how we are going to study. Lately, we are being bombarded with assignments and quizzes without being taught, and when you need help you can't even find lecturers at their office lines. So, I can say we are on our own. (Participant 2)

With online learning, students are of the view that there is less guidance from academics than when they are on campus. Students have the flexibility to schedule their learning activities at a convenient time and determine what to learn as well. To explain this, one participant said: 
Maphalala, M. C. et al. Online Learning as a Catalyst for Self-directed Learning in Universities during the COVID-19 Pandemic

Since we moved to online learning, we find ourselves in a situation in which our lecturers cannot hold us by the hand to tell us what we should be doing and when. You are just given activities and submission deadlines; it becomes your responsibility to teach yourself and work hard to meet the deadlines. (Participant 5)

SDL skills include the ability to manage learning activities without being guided by others, as well as learning at one's own pace according to one's needs and preferences. This makes SDL more relevant for the students' needs. To support this, one participant said:

Many students find it difficult at first to organize and motivate themselves to work on their own, but as time goes on, they soon realize that there is no other way but to find means to continue learning on your own from home, according to suitable times. I work better at night because I use the night surfer data option and it's always quiet. (Participant 7)

While students embrace taking responsibility for their learning, they feel that academics must come to the party and provide more guidance than they do. One participant explained:

I recognize the importance of studying independently as a university student, but I need my lecturers to guide us and make themselves available when we need them. Now that we are learning online some of them are nowhere to be found. (Participant 2)

Another participant added:

We have found ways to manage our work daily without someone checking on us and reminding us about the due dates; you just have to develop and maintain the discipline needed for self-learning. (Participant 8)

SDL empowers students to take charge of their learning, with students making their own decisions regarding their learning paths.

\section{Theme 3: Learning approaches}

During the emergency transition from face-to-face to online learning, students showed enhanced self-direction, accountability, and motivation. They had to adopt various learning approaches to assist them to navigate online learning. Students are aware that they need to collaborate with other students to enhance their learning. One student teacher agreed to this, saying:

You cannot completely work independently; from time to time you have to share ideas with others in your class. (Participant 10)

Collaborative learning is an integral part of students' learning; the students felt they learnt by sharing ideas and knowledge. One participant confirmed:

I find it easy to learn when we work in a group. We formed a WhatsApp group where we exchange ideas and answer certain assignments either as a chat or a group call. It is enjoyable and we make jokes about the challenges that we have whilst we are learning. (Participant 1 ) 
Maphalala, M. C. et al. Online Learning as a Catalyst for Self-directed Learning in Universities during the COVID-19 Pandemic

The material introduced by lecturers is often discussed further in these group discussions. Group discussions are used by students to reinforce learning and solve problems as part of SDL. One of the participants had this to say:

Some lecturers just upload materials online with very little guidance and explanation so we have to work in groups to figure out the new information on our own so that if we get stuck, we can ask the class rep to communicate with the lecturer concerned. (Participant 3)

Students also organized themselves into groups to engage in peer-led learning, where a student who was good in a particular aspect would facilitate learning. Another participant said:

Some students know certain aspects or modules better than us, so we ask those students to assist us with those, so if they are confident to facilitate those areas but lack some information, we have to consult the lecturers. (Participant 6)

\section{Theme 4: Self and peer assessment}

Students used self-assessment and peer assessment as strategies to take more control of their learning. These forms of assessment are useful for students to continually assess their learning progress to determine gaps and work towards the improvement of their learning.

Peer assessment was found to be beneficial for the students' learning, as students critiqued and provided feedback on each other's work to find areas that might need improvement and enhance learning. One participant confirmed:

I think getting feedback from your fellow students is very useful. Before I can submit any activity for assessment, I ask my group members to check my work and give me an honest opinion of what they think about it, and more often than not, they have valuable input to make which assists to improve my work. (Participant 1)

Participant 8 explained:

Peer assessment can therefore be a valuable way of providing more frequent and relevant formative feedback that students can act upon. (Participant 8 )

Self-directed students are self-reliant, and they recognize that reflection is essential for meaningful learning. The students diagnosed their learning through reflection to continually improve in their studies. To support this, one participant said:

I don't have to wait for somebody else to tell me that my work is not up to standard, so before I hand in any assignment to my lecturer I go through it to make sure that the answers are correct, and I consult Google or my books to verify. (Participant 4)

Self-assessment allows students to take an active role in their learning. Students should assess their strengths and weaknesses honestly to enhance learning. This was confirmed by one participant who had the following to say: 
Maphalala, M. C. et al. Online Learning as a Catalyst for Self-directed Learning in Universities during the COVID-19 Pandemic

Now that we don't constantly interact with lecturers, I have learned to assess my own work. It makes you see where you are weak so that you can focus on those areas that need to improve. Where I am not sure, my classmates can assist, or ask in the WhatsApp group chat if my thinking is correct. (Participant 8)

\section{Discussion}

The findings reveal that both students and academics were not adequately prepared for the transition to online learning from face-to-face learning. Students particularly encountered difficulties navigating the SDL activities on the learning management system on their own. However, the introduction of online learning empowered students, fostering independent and collaborative learning amongst themselves with minimal assistance from the academics. The discussion of findings placed more emphasis on four themes to answer two main research questions. It is evident that students demonstrated enhanced self-direction, accountability and motivation through adopting various learning approaches to assist them to navigate online learning; these included collaborative learning (group discussions, peer-led learning). To continuously assess and monitor their own learning progress, students used self-assessment and peer assessment as strategies, these forms of assessment were useful for students in determining the gaps and working towards the improvement of their learning. This allowed them to play a central role in their learning. SDL requires students to have the confidence to pursue and engage in learning activities which are all influenced by intrinsic motivation. Online learning during the COVID-19 pandemic has actually motivated the students to engage in learning that is self-directed (Baez, 2019; Baticulon et al., 2021). The discussion of findings in the next paragraph focuses on the integration of self-directed learning in the online learning theme.

From the findings, it would seem that students were not prepared to play a central role in their learning when the transition from face-to-face to online learning was forced on them, according to the results. The integration of SDL into online learning enhanced students' independence as they learnt on their own, using the resources on the online learning platform. Self-directed learners are more engaged in learning activities such as reading online learning materials, completing classroom assignments, and preparing and reviewing learning achievements (Geng et al., 2019). In SDL, high-level self-management is crucial, and students must use a variety of methods to deal with a variety of issues (Lee \& Teo, 2010; Ohlin, 2019). It is therefore of critical importance that students are prepared for both online learning and SDL, as this allows students to take care of their own learning, and build successful independent learning strategies. Online readiness allows students to leverage the LMSs and new technologies for learning. To prepare and foster SDL, students need guides, support and cues to help them navigate self-directed activities in both on- and offline environments. SDL empowers students to schedule their learning activities at a convenient time, and determine what to learn as well (Ohlin, 2019; Roberson et al., 2021). While SDL requires students to take responsibility for their learning, academics should not abdicate their responsibility to provide constant guidance and constructive feedback to students on their learning. 
Maphalala, M. C. et al. Online Learning as a Catalyst for Self-directed Learning in Universities during the COVID-19 Pandemic

The urgent need to move from face-to-face to online learning saw increased responsibility for self-direction and motivation on the part of the students. They had to adopt various learning approaches to assist them to navigate online learning. Collaborative learning was listed as a crucial component of their online learning (Kalimullina et al., 2021). Peer and self-assessment have been found to be beneficial in encouraging student-centered learning (Baticulon et al., 2021; Ohlin, 2019) because they enable students to reflect on their own learning and levels of comprehension, as well as recognize areas where they need to develop. This is a transition in learning from teacher-centered to student-centered, in which students identify their own goals and the steps needed to achieve them. Peer assessment helps to improve learning outcomes (Sanchez, Atkinson et al., 2017; Li et al., 2020). Self-assessment helps students diagnose their learning through reflection to continually improve in their studies (Baez, 2019).

The COVID-19 pandemic disrupted the academic programs of higher education institutions worldwide/ However, with every crisis comes an opportunity to transform. The transition to online learning accelerated self-directed learning to motivate and engage students in their learning more critically and independently. The findings affirm that a student-centered approach is a necessity to empower self-directed learners to be active participants rather than passive recipients of knowledge (Roberson Jr, 2021; Sze-yenga \& Hussain; 2010). Self-directed learning therefore becomes necessary to enhance competency in the new generation of students.

Online learning has transformed how teaching and learning are facilitated in higher education. In the traditional face to face learning environment, the instructor was regarded as a source of knowledge. The online learning environment has provided a fair share of autonomy and independence amongst students. This is in line with self-directed learning which requires students to operate in an independent and self-regulated manner to achieve meaningful learning. Online learning has facilitated a paradigm shift from teacher-centered to more student-centered teaching and learning approaches in which students are assisted and guided to learn independently. Therefore, the findings reveal that the overreliance on traditional faceto-face learning has been a limitation to students' self-initiative, self-reliance, self-reflection, leaner centeredness, autonomy, and independent learning that are all hallmarks of selfdirected learning. This study identities collaborative learning, independent learning, self and peer assessment as critical enforcers of enhanced self-direction amongst the students in an online learning environment. Putri et al. (2021) argue that in a world where alternative education environments are possible, online learning is an option that has allowed the teaching and learning process to continue amid the Covid-19 Pandemic). Akhmetshin et al. (2021) concur that transition to online learning was the only option out of the pandemic quagmire.

\section{Conclusion}

The unprecedented disruption of face-to-face learning in educational institutions provided many possibilities to foster SDL through online learning. Most universities had benefited from the emergency transition to an online learning system during the Covid-19 lockdown. Confirm that during the lockdown, both students and teachers believed that online learning modalities had aided student-centeredness. The students had evolved into self-directed learners who could learn at any time of day. Universities have accordingly adopted LMSs to bridge the SDL experiences and the online environment and connect students and lecturers in real-time. This 
Maphalala, M. C. et al. Online Learning as a Catalyst for Self-directed Learning in Universities during the COVID-19 Pandemic

finding is consistent with the current studies which that conclude that improvement in the use of LMS highlights endless possibilities for students to access much-needed academic information. This, therefore, calls for universities to revise programs to include pedagogies to foster SDL, empower students and enhance their learning capabilities. The findings again acknowledge that much still needs to be done to enhance the quality of internet connectivity and provide free $\mathrm{Wi}-\mathrm{Fi}$ in local libraries and hotspots in small towns and cities to foster SDL. Most SDL proponents believe that universities that have successfully used online learning prioritized access to data for all their students. Issues that remain as "work in progress" for further investigation include exploring more deeply the SDL and students' performance, and how the support provided automated help speed up communication to students in resolving their daily technical challenges with their devices and academic activities. Understanding how and in what contexts such complex epistemological and ontological shifts occur is key for creating the type of SDL that may be needed to navigate online learning during lockdown and any emergency.

\section{References}

Adinda, D., \& Mohib, N. (2020). Teaching and instructional design approaches to enhance students' self-directed learning in blended learning environments. The Electronic Journal of e-Learning, 18(2), 162-174. https://doi.org/10.34190/EJEL.20.18.2.005

Akhmetshin, E., Vasilev, V., Zekiy, A., \& Zakieva, R (2021) Massive Open Online Courses as the Initial Stage of Development of a Digital University. Journal of Social Studies Education Research, (12)2, 126-151.

Baez, Z. D. (2019). ICT and its purpose in the pedagogical practice. Research in Social Sciences and Technology, 4(2), 83-95. https://doi.org/10.46303/ressat.04.02.6

Bates, A.W. (2019). Teaching in a digital age: Guidelines for designing teaching and learning (2nd ed.). Vancouver: BC Campus.

Baticulon, R.E., Sy, J.J., Alberto, N.R.I., Mabulay, R.E.C., Rizada, L.G.T., Tiu, C.J.S., Clarion, C.A., \& Reyes. J.C.B. (2021). Barriers to online learning in the time of COVID-19: A national survey of medical students in the Philippines. Med. Sci. Educ. 31, 615-626. https://doi.org/10.1007/s40670-021-01231-z

Bonfield, C. A., Salter, M., Longmuir, A., Benson, M., \& Adachi, C. (2020). Transformation or evolution? Education 4.0, teaching and learning in the digital age. Higher Education Pedagogies, 5(1), 223-246. https://doi.org/10.1080/23752696.2020.1816847

Bonk, C.J., \& Lee, M.M. (2017). Motivations, achievements, and challenges of self-directed informal learners in open educational environments and MOOCs. Journal of Learning for Development, 4(1), 36-57. https://jl4d.org/index.php/ejl4d/article/view/195/188.

Braun, V., \& Clarke, V. (2006). Using thematic analysis in psychology. Qualitative Research in Psychology, 3(2), 77-101. https://doi.org/10.1191/1478088706qp063oa

Broadbent, J. (2017). Comparing online and blended learner's self-regulated learning strategies and academic performance. The Internet and Higher Education, 33, 24-32.

Crawford, J., Butler-Henderson, K., Rudolph, J., Glowatz, M., Burton, R., Malkawi, M., Magni, P., \& Lam, S. (2020). Covid-19: 20 countries' higher education intra-period digital pedagogy responses. Journal of Applied Learning \& Teaching, 3(1), 9-28. 
Maphalala, M. C. et al. Online Learning as a Catalyst for Self-directed Learning in Universities during the COVID-19 Pandemic

Creswell, J.W., \& Plano-Clark, V.L. (2011). Designing and conducting mixed methods research (2nd ed.). Thousand Oaks, CA: SAGE.

De Vos, A. S., Strydom H., Fouche, C. B., \& Delport C. S. L. (2011). Research at grass roots. Pretoria: Van Schaik.

Efron, S. E. \& Ravid, R. (2013). Action Research in Education: A Practical Guide. New York, NY: Guilford Press. 268 pages.

Flick, U. (2009). An Introduction to Qualitative Research. London: Sage Publications

Geng, S., Law, K. S. \& Niu, B. (2019). Investigating self-directed learning and technology readiness in blending learning environment. International Journal of Educational Technology in Higher Education, 16, 17. https://doi.org/10.1186/s41239-019-0147-0

Huang, R., Liu, D., Tlili, A., Knyazeva, S., Chang, T. W., Zhang, X., Burgos, D., Jemni, M., Zhang, M., Zhuang, R., \& Holotescu, C. (2020). Guidance on open educational practices during school closures: Utilizing OER under Covid-19 pandemic in line with UNESCO OER recommendation. Smart Learning Institute of Beijing Normal University.

Ibrahim, N., Adzra'ai, A., Sueb, R., \& Dalim, S. F. (2019). Trainee teachers' readiness towards 21st-century teaching practices. Asian Journal of University Education, 15(1), 1-12.

Kalimullina, O., Tarman, B. \& Stepanova, I. (2021). Education in the Context of Digitalization and Culture: Evolution of the Teacher's Role, Pre-pandemic Overview. Journal of Ethnic and Cultural Studies, 8(1), 226-238. DOI: http://dx.doi.org/10.29333/ejecs/629

Khoza, S. (2019). Lecturers' reflections on curricular spider web concepts as transformation strategies: Transformation of higher education institutions in post-apartheid South Africa. London: Routledge.

Knowles, M.S. (1980). The modern practice of adult education: From pedagogy to andragogy (2nd ed). New York: Cambridge Books.

Lee, C.B., \& Teo, T. (2010). Fostering self-directed learning with ICT. In C.S. Chai, \& Q. Wang (Eds.), ICT for self-directed and collaborative learning (pp. 39-51). Pearson.

Lee, K., Tsai, P., Chai, S., \& Koh, JH. (2014). Students' perceptions of self-directed learning and collaborative learning with and without technology. Journal of Computer Assisted Learning, 30(5), 425-437. https://doi.org/10.1111/jcal.12055

Li, H., Xiong, Y., Hunter, C. V., Guo, X., \& Tywoniw, R. (2020). Does peer assessment promote studnt learning? A meta-analysis. Assessment \& Evaluation in Higher Education, 45(2): 193-211. https://doi.org/10.1080/02602938.2019.1620679

Mgqwashu, E. (2017). Universities can't decolonise the curriculum without defining it first. www.conversation.com/universities-cant-decolonise-the-curriculumwithout-definingit-first-63948

Morris, T.H., \& Rohs, M. (2021). The potential for digital technology to support self-directed learning in the formal education of children: A scoping review. Interactive Learning Environments. https://doi.org/10.1080/10494820.2020.1870501

Mpungose, C. (2019). Is Moodle a platform to decolonise the university curriculum? Lecturers' Reflections. Africa Education Review, 17(1), 100-115, https://doi.org/10.1080/18146627.2018.1479645

Mpungose, C. (2020). Emergent transition from face-to-face to online learning in a South African university in the context of the coronavirus pandemic. Humanities and Social Sciences Communications, 7, a113. https://doi.org/10.1057/s41599-020-00603-x 
Maphalala, M. C. et al. Online Learning as a Catalyst for Self-directed Learning in Universities during the COVID-19 Pandemic

Mukhtar, K., Javed, K., Arooj, M., \& Sethi, A. (2020). Advantages, limitations and recommendations for online learning during COVID-19 pandemic era. Pakistan Journal of Medical Sciences, 36(COVID19-S4), 27-S31.

https://doi.org/10.12669/pjms.36.COVID19-S4.2785

Nieuwenhuis, J. (2020). Editorial. Perspectives in Education, 38(2), i-iii. https://doi.org/10.18820/2519593X/pie.v38.i2.ed

Ohlin, C. (2019). Information and communication Technology in a global world. Research in Social Sciences and Technology, 4(2), 41-57. https://doi.org/10.46303/ressat.04.02.4

Pham, H.H, \& Ho, T.T.H. (2020). Toward a "new normal" with e-learning in Vietnamese higher education during the post COVID-19 pandemic. Higher Education Research \& Development, 39(7). https://doi.org/10.1080/07294360.2020.1823945

Pilot, D. F., \& Hungler, B. P. (1999). Nursing research: principles and methods. Phildelphia: JB Lippincott Company.

Putri, K.Y.S., Fathurahman, H., Safitri, D., \& Sugiyanta, L. (2021) The Use the Elaboration phase in ICT and Social Studies to Educate Junior High School Students about the Covid 19 Pandemic. Journal of Social Studies Education Research, 12 (2),100-125

Rashid, T., \& Asghar, H.M. (2016). Technology use, self-directed learning, student engagement and academic performance: Examining the interrelations. Computers in Human Behaviour, 63, 604-612.

Roberson Jr., D.N., Zach, S., Choresh, N., \& Rosenthal, I. (2021) Self-directed learning: A longstanding tool for uncertain times. Creative Education, 12, 1011-1026. https://doi.org/10.4236/ce.2021.125074.

Sanchez, C.E., Atkinson, K.M., Koenka, A.C., Moshontz, H., \& Cooper, H. (2017). Self-grading and peer-grading for formative and summative assessments in 3rd through 12th grade classrooms: A meta-analysis. Journal of Educational Psychology, 109(8), 1049-1066. https://doi.org/10.1037/edu0000190

Sze-yenga, F., \& R Hussain, R.M.R. (2010). Self-directed learning in a socio-constructivist learning environment. Procedia Social and Behavioral Sciences, 9, 1913-1917.

Tadesse, S., \& Muluye, W. (2020). The impact of COVID-19 pandemic on education system in developing countries: A review. Open Journal of Social Sciences, 8(10), 159-170.

Udosen A.E, (2014). Learner autonomy and curriculum delivery in Higher Education: the case of University of Uyo, Nigeria. International Education Studies, 7(3), 40-50.

Voskampa, A., Kuiperb, E., \& Volman, M. (2020). Teaching practices for self-directed and selfregulated learning: case studies in Dutch innovative secondary schools. Educational Studies. https://doi.org/10.1080/03055698.2020.1814699

Waghid, F. (2018) Action research and educational technology: Cultivating disruptive learning. South African Journal of Higher Education, 32(4), 1-11.

Xue, E., Li, J., \& Xu, L. (2020). Online education action for defeating COVID-19 in China: An analysis of the system, mechanism, and mode. Educational Philosophy and Theory, 113. https://doi.org/10.1080/00131857.2020.1821188 